\title{
LOS CENTROS DE INTERÉS TURÍSTICO NACIONAL Y EL DESPEGUE DEL TURISMO DE MASAS EN ESPAÑA
}

\author{
Luis Galiana Martín \\ Diego Barrado Timón \\ Departamento de Geografía \\ Universidad Autónoma de Madrid
}

\section{RESUMEN}

En los años cincuenta se define un sistema de planificación turístico territorial, aprobado definitivamente en los sesenta con la Ley de Centros y Zonas de Interés Turístico Nacional (CyZITN), que pretendía conectar las previsiones ligadas a la política económica y al desarrollo turístico con la ordenación del territorio. Se intentó un ambicioso modelo que desde el punto de vista técnico alcanzó un notable desarrollo, aunque fracasó en su vertiente político-legislativa quedando finalmente reducido a poco más que una figura destinada a amparar y promocionar asentamientos urbano-turísticos denominados Centros de Interés Turístico Nacional. Pero a pesar de ese relativo fracaso, estos Centros de Interés Turístico Nacional tuvieron una considerable importancia en algunos ámbitos regionales del litoral y en determinados modelos de desarrollo turístico, caso de la alta montaña y el esquí alpino.

Palabras clave: Centro de Interés Turístico Nacional, planificación territorial, planificación turística, turismo, Geografía, España.

\section{SUMMARY}

The research aims to analyse a physical tourism planning system conceived during the 1960s and finally endorsed in the 1970s by the C\&ZITN Law. This system attempted to link economic and tourism development policies with physical planning forecasts. It was proposed an ambitious model, well developed from the technical point of view, although it fails in implementing within the regulation scope. Lastly it hardly became something more than a legal tool supporting tourism-urban settlements labelled as «National Tourism Targeted Centres». In spite of the relative above-mentioned failure, these National Tourism Targeted Centres have a meaningful influence on some coastal regions and specific tourism development models, which was the case of high mountain and alpine skiing resorts. The results of those developments are also included in this research. 
Key words: Centro de Interés Turístico Nacional, spatial planning, tourism planning, tourism, Geography, Spain.

\section{El Ministerio de Información y Turismo y la formulación de una verdadera orde- nación territorial turística en España}

En julio de 1962, el que fue presidente de la Xunta de Galicia, Manuel Fraga Iribarne, entró en el gobierno español ocupando la cartera ministerial de Información y Turismo. Siete años después había hecho del turismo la primera industria nacional, según señala su biografía oficial institucional. Esta afirmación, no por discutible menos significativa, está reflejando una extendida opinión: el importante papel que la administración turística española jugó en el despegue del turismo de masas en España.

Por nuestra parte, creemos más bien que así pudo llegar a ser. Desde la administración se intentó un ambicioso modelo de ordenación y fomento de la actividad turística, que abarcaba desde la promoción de la actividad a la planificación territorial de los principales ámbitos receptores. En este sentido, se planteó un admirable edificio técnico-jurídico para su ejecución que, sin embargo, fracasó en su vertiente político-administrativa. Por el camino quedaron, no obstante, algunas realizaciones de gran interés y repercusión posterior. Una de ellas es, sin lugar a dudas, la promoción de un considerable número de asentamientos turísticos (los denominados Centros de Interés Turístico Nacional) que abrieron la vía a determinados modelo de desarrollo de esta actividad y supusieron la puesta en valor de importantes ámbitos del litoral español.

\subsection{La inserción de la planificación del turismo en la más amplia ordenación económico- social}

El fuerte impulso político que Fraga imprimió al Ministerio de Información y Turismo (MIT) supuso, además de un importante afianzamiento administrativo del sector turístico (Cuétara, 1985), que esta actividad comenzara a tener voz propia, reclamando ser considerada expresamente en la fijación de determinadas políticas estatales. Esta voluntad se hizo particularmente evidente cuando se reclamó para el turismo un papel protagonista en la planificación económica estatal desarrollada desde principios de los años sesenta (Planes de Desarrollo Económico y Social) (PDES).

Este deseo aparece ya en la incipiente planificación económica que se desarrolló en España en los años cuarenta y cincuenta a cargo de la Secretaría General para la Ordenación Económico-Social (Plan Badajoz, 1952; Plan Jaén, 1953), donde se planteó la necesidad de formular acciones administrativas dirigidas a la ordenación y fomento de la actividad turística. La redacción de un Plan Nacional de Turismo (1955), en el que se introduce el concepto de Zona de interés turístico, al tiempo que se formulan principios regionales de actuación, es reflejo de esta voluntad. No obstante, esta línea no se afianzará hasta la creación del Ministerio de Información y Turismo (1962) que potenció la ya existente Comisión Interministerial del Turismo, directamente implicada en informar y fundamentar la acción turística en el marco de los Planes de Desarrollo.

Incardinar el turismo en el proceso de planificación económica que se lanzaba en aquellos años presentaba no pocas dificultades, dada la insuficiente reflexión teórica sobre el papel que esta actividad podía llegar a ejercer en los procesos de desarrollo y su generalizada consideración como un sector de escasa solidez para apoyar el proceso de despegue económico. En efecto, la incorporación de las principales teorías de desarrollo regional, preocupadas 
por los desequilibrios espaciales y el reconocimiento de la necesidad de intervenir por parte de los poderes públicos para el desarrollo de las regiones más atrasadas, se formalizó en España, como es de sobra conocido, en polos de crecimiento ligados preferentemente a la actividad industrial. Por otro lado, el informe del Banco Mundial de 1963 sobre la economía española, además de dedicar al turismo un reducido número de páginas, lo calificó como un fenómeno coyuntural sobre el que no podía reposar una estrategia sólida de desarrollo. Así las cosas, el turismo tuvo que buscar su acomodo en una planificación económica de preferente desarrollo industrial, pasando a representar un papel claramente instrumental: convertirse en fuente de divisas para favorecer la necesaria inversión en bienes de equipo para modernizar la base industrial.

Pero frente a esta generalizada concepción teórica del turismo como una actividad volátil, el evidente peso que fue adquiriendo en la economía española y la importancia y solidez del turismo exterior en el equilibrio de la balanza de pagos, empezaron a apoyar el discurso de la administración turística (MIT, 1962). Como resultado, desde la planificación económica se fueron incorporando planteamientos de ordenación y fomento del sector, que ya se estaban desarrollando desde la propia administración turística, otorgándole una legitimidad de la que carecía y propiciando el posterior desarrollo de una normativa adecuada para instrumentar la práctica territorial de la política turística.

El primero de los aspectos que se retomó fue la necesidad de establecer un marco director de los procesos espaciales que se derivasen de los nuevos desarrollos turísticos. En esta línea, la Comisión Interministerial del Turismo ${ }^{1}$ (CIT) se lanzó al desarrollo de un planeamiento territorial director, abordando la redacción de otro Plan Nacional de Turismo, directamente incardinado en la planificación económica-social. Este instrumento debía suministrar el adecuado marco territorial para la acción de fomento de la actividad turística por parte del Estado, estableciendo para ello un conjunto de ponencias regionales. Aunque los resultados de estas ponencias finalmente no se concretaron en un Plan Nacional, fueron un instrumento de singular importancia en el proceso de planificación territorial turística, desarrollando fuertes principios espaciales en su actuación que aún hoy perduran (Costa de Huelva).

Las ponencias iniciaron sus trabajos en 1963, con dos claros principios territoriales en la orientación del desarrollo turístico:

1) La promoción turística de la montaña, a través de estaciones turísticas de invierno. La Ponencia I se dedicó a Sierra Nevada, y la XII a Navacerrada. Igualmente se encargó un informe que aconsejó la intervención en Pirineos en una segunda fase.

2) La dinamización de zonas litorales poco afectadas todavía por el 'boom' turístico y dotadas de buenas condiciones naturales: el Mar Menor (Murcia), la costa de Huelva, Peñíscola y Canarias.

Cada una de estas zonas debería desarrollarse de acuerdo a la programación y a la ordenación espacial definida en su correspondiente Plan Director, que comenzaron a redactarse de inmediato.

Además de esta intervención territorial promovida desde el Estado, también en este momento se definen algunos instrumentos y acciones directas de apoyo a esta política. Por un lado se favorece la iniciativa privada estableciendo una serie de ventajas económicas y jurídicas para impulsar líneas de inversión que se ajustasen a las necesidades de la política turística y económica del Estado. La traducción directa fue el arranque de una fórmula de

1 La Comisión Interministerial de Turismo (CIT) fue creada en 1954. Dependía funcionalmente del MIT, y en ella participaban los demás ministerios. A partir de 1962 la CIT reactivó su funcionamiento, quedando encargada de plantear los trabajos preparatorios de un Plan Nacional de Turismo. 


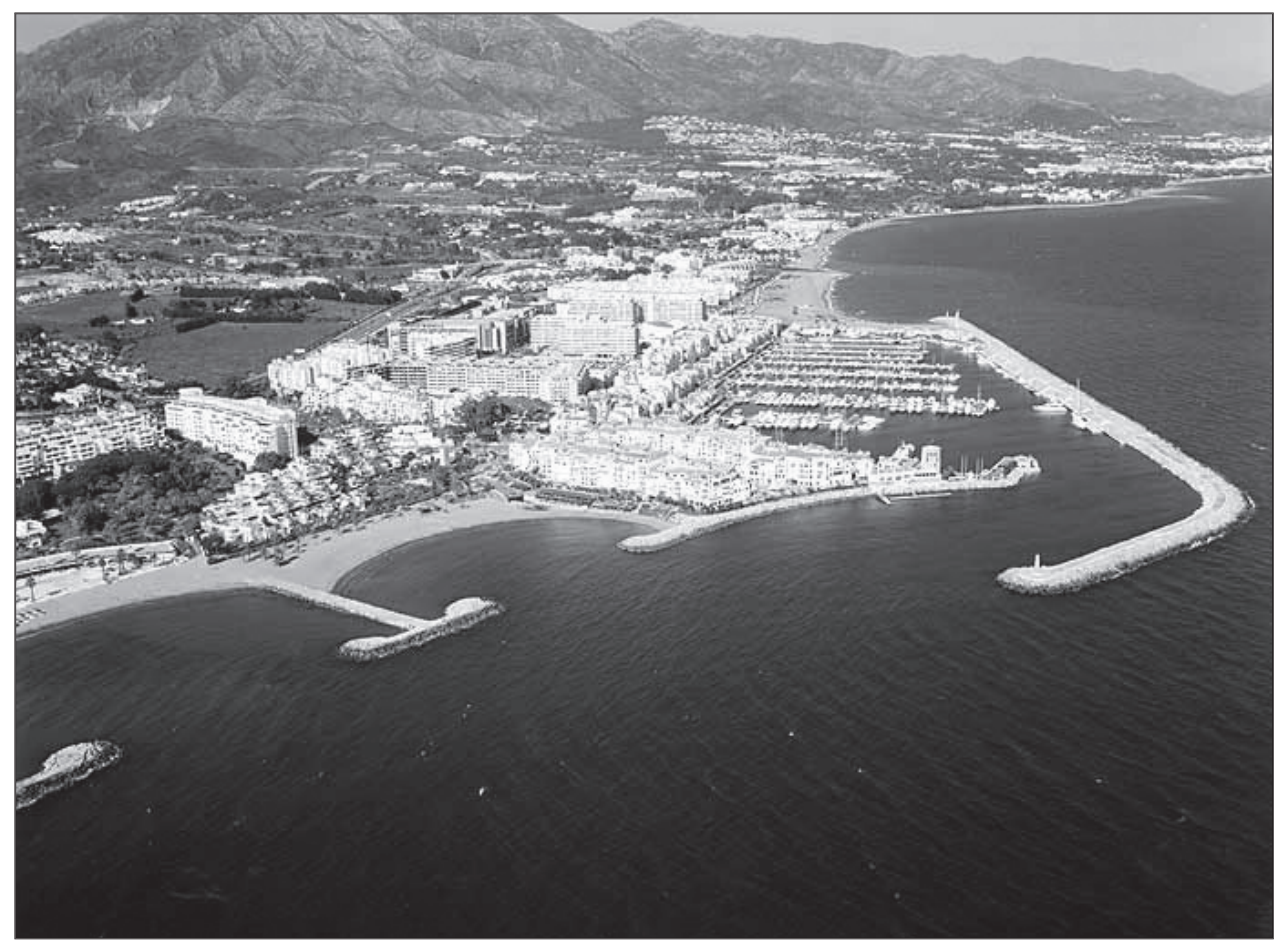

Nueva Andalucía. Puerto Banús (Ministerio de Medio Ambiente. Guía de playas españolas. http:// www.mma.es/costas/guia_playas/)

crédito prioritario para el alojamiento turístico que se prolongará en el tiempo. Se señalan igualmente las líneas de intervención directa por parte de la administración: obtención de suelo (vía expropiación o desafectando bienes públicos — Costa de Huelva-) para su puesta a disposición a los inversores privados; realización de infraestructuras generales; y, finalmente, y sólo en último caso, promoción pública directa de urbanizaciones turísticas allí donde se considerase necesario ante la inacción de la inversión privada.

En resumen, la política turística impulsada desde el MIT obtiene su definitivo visado al quedar incluida en el PDES. La apertura a los mercados internacionales de nuevas áreas turísticas se convierte en una prioridad, y para ello se invoca la necesidad de una acción rápida, urgente, convenientemente coordinada por parte del Estado. Para encauzar este proceso se planteará un modelo de desarrollo soportado por una legislación específica: la ley de Zonas y centros de Interés Turístico Nacional.

\subsection{La Ley de Zonas y Centros de Interés Turístico Nacional: una legislación específica para abordar el desarrollo de las zonas turísticas}

Junto a la necesidad de establecer planes directores que dirigiesen las nuevas implantaciones turísticas se vuelve a plantear la peculiaridad urbanística del turismo, y la necesidad de una normativa ex profeso que atendiese a sus particularidades y facilitase la intervención pública para la creación de infraestructuras básicas (PDES 1964-67). La respuesta legislativa 
fue la Ley de Zonas y Centros de Interés Turístico Nacional ${ }^{2}$, que creaba un sistema de planificación territorial propio y diferenciado.

La ley retoma el interesante concepto de Zona de Interés Turístico Nacional (ZITN) (que ya se manejaba desde un Anteproyecto de 1955), entendida como un espacio geográfico amplio y adecuado para su promoción turística, bien dotado, y que dejado a la acción espontánea de la iniciativa privada bien pudiera frustrarse en su desarrollo (Memoria MIT, 1962). Desgraciadamente la ZITN nunca fue un concepto técnicamente bien definido, mezclándose y confundiéndose con frecuencia la promoción entendida como publicidad con la verdadera creación de productos y su integración territorial. Es posible que este deficiente desarrollo teórico de la Zona frente al más simple concepto de Centro de Interés Turístico Nacional (CITN), producto urbano-turístico individualizado con más de 500 plazas y 10 ha de superficie, supusiese la preeminencia de éstos frente a aquéllas.

El resultado fue un escaso protagonismo de las Zonas frente a los Centros; no se llegó a aprobar finalmente ninguna, a pesar de que se avanzó notablemente en las de la Costa del Sol y la Costa Brava. Por el contrario, hasta 1975 se aprobaron 78 CITN. Estas iniciativas se beneficiaban de ciertos incentivos fiscales y de la posibilidad de transformar el suelo rústico en urbanizable a través de la redacción de un Plan de Ordenación Urbana; la contrapartida exigida a los promotores era garantizar una calidad del producto final muy por encima de lo habitual en aquellos años.

Esta figura contó con detractores desde su promulgación, interpretándola como una ley que bordeaba el sistema de planificación territorial habitual para facilitar los procesos de desarrollo turístico (Fernández, 1965; Serrano, 1966; Terán, 1982). Realmente fue algo más que eso. Fue un intento de crear un modelo propio, diferente de la Ley del Suelo, con sus propios presupuestos conceptuales y técnicos. El esquema de partida era el siguiente: un Plan de Ordenación Territorial y Urbana cumpliría las funciones de plan director para un conjunto comarcal más o menos amplio (las ZITN) definiendo además los CITN; con posterioridad el Plan de Ordenación Urbana de los CITN aseguraría la correcta dotación de infraestructuras y servicios de cada uno de los polos de desarrollo elegidos. Se creaba, por tanto, un tipo de plan de escala intermedia (plan de ordenación territorial y urbana) que conectaba la planificación turística y la territorial.

Sin embargo, tanto la traslación a la propia ley, como su desarrollo posterior, se alejaron de este esquema: los CITN, de promoción privada, se desarrollaron sin la previa declaración de ZITN, rompiéndose el esquema de coordinación previsto. La ambiciosa pretensión de establecer un marco director general para el desarrollo territorial del turismo quedó reducida a establecer una estructura para la ordenación interna de cada uno de los núcleos urbanoturísticos que optasen a la declaración de interés turístico nacional. Pero a pesar de ello, el desarrollo de ciertas zonas litorales no puede explicarse sin la completa consideración de este modelo de planificación, como veremos más adelante.

\section{La aplicación de la ley y sus efectos territoriales}

En los doce primeros años de aplicación de la ley (1964-1975) se declaran 78 CITN, lo que supuso un programa de preparación de suelo de más de 22.000 ha con una capacidad de alojamiento de casi 890.000 plazas. La distribución temporal de los centros aprobados muestra claramente una tendencia creciente en los primeros años de aplicación de la ley (hasta 1968), para posteriormente iniciarse un progresivo descenso que lleva hasta su casi

2 Ley 197/1963, de 28 de diciembre. Su reglamento fue aprobado por Decreto 4.294/1964, de 23 de diciembre. 


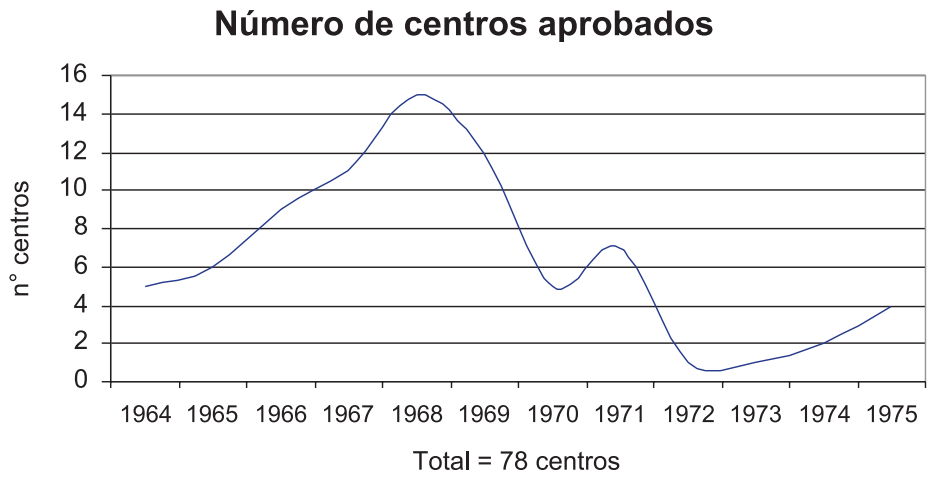

falta de aplicación a principios de los setenta, produciéndose un leve repunte final en 1975 (4 centros, entre los cuales algunos de grandes dimensiones: La Alcaidesa en Tarifa, o las estaciones invernales de Astún y Valcotos) ${ }^{3}$.

La mayoría de centros son de pequeños dimensiones, tanto por la superficie afectada como por el número de plazas previstas (menores de 150 ha y 10.000 plazas); sin embargo, los grandes centros de interés turístico, ya sea considerando su extensión (más de 700 ha) o el número de plazas previstas (más de 30.000), supusieron la mayor parte de la superficie desarrollada (61,1 por 100) y más de la mitad de las plazas previstas.

DISTRIBUCIÓN POR TAMAÑO Y NÚMERO DE PLAZAS DE LOS CITN

\begin{tabular}{|c|c|c|c|c|c|c|}
\hline Tamaño & $\mathbf{N}^{\circ}$ de centros & $\%$ & Superficie (ha) & $\%$ & Plazas previstas & $\%$ \\
\hline$>700$ ha & 12 & 15,4 & 13.629 & 61,1 & 355.981 & 40,0 \\
\hline $300-700$ ha & 8 & 10,3 & 3.429 & 15,4 & 165.994 & 18,7 \\
\hline $150-300$ ha & 11 & 14,1 & 2.250 & 10,1 & 136.507 & 15,3 \\
\hline$<150$ ha & 47 & 60,3 & 3.006 & 13,5 & 231.158 & 26,0 \\
\hline \multicolumn{7}{|l|}{$N^{o}$ de plazas } \\
\hline$>30.000$ plazas & 11 & 14,1 & 9.270 & 41,5 & 468.580 & 52,7 \\
\hline $15-30.000 \ll$ & 5 & 6,4 & 1.402 & 6,3 & 96.190 & 10,8 \\
\hline $10-15.000 \ll$ & 9 & 11,5 & 1.931 & 8,6 & 108.255 & 12,2 \\
\hline $5-10.000 \ll$ & 20 & 25,6 & 5.473 & 24,5 & 132.983 & 14,9 \\
\hline$<5.000 \ll$ & 33 & 42,3 & 4.238 & 19,0 & 83.632 & 9,4 \\
\hline Total & 78 & 100,0 & 22.314 & 100,0 & 889.640 & 100,0 \\
\hline Valor medio & - & - & 286,1 ha & - & 11.407 plazas & - \\
\hline
\end{tabular}

FUENTE: Centro de Documentación Turística de España (Secretaría General de Turismo).

3 A partir de esta fecha aún se producirá alguna aprobación aislada por parte de la administración estatal: Son Xigala (1978), en el municipio de Palma, y Mondragó (1981) en Santanyí (RIPOLL, 1990). Tras las transferencias de competencias en materia turística, también por parte de algunas Comunidades autónomas (pues la ley ha estado vigente hasta 1991): Ciudad Patricia (1983), en Benidorm (TORRES, 1991, pág. 37). 


\section{CENTROS DE INTERÉS TURÍSTICO NACIONAL APROBADOS (1964-75)}

\begin{tabular}{|c|c|c|c|c|}
\hline CENTRO & MUNICIPIO (Provincia) & $\begin{array}{l}\text { APROBA- } \\
\text { CIÓN }\end{array}$ & $\begin{array}{l}\text { SUP. } \\
\text { (ha) }\end{array}$ & PLAZAS \\
\hline \multicolumn{5}{|l|}{ Zonas litorales con débil ocupación turística } \\
\hline GUADACORTE & LOS BARRIOS (Cádiz) & $23 / 12 / 65$ & 864 & 67.240 \\
\hline ISLA CANELA & AYAMONTE (Huelva) & $10 / 10 / 64$ & 1.100 & 46.500 \\
\hline EL PORTIL & CARTAYA Y PUNTA UMBRÍA (Huelva) & $22 / 1 / 68$ & 520 & 40.000 \\
\hline LA ALCAIDESA & SAN ROQUE (Cádiz) & $14 / 1 / 75$ & 1.540 & 37.440 \\
\hline BENAHAVIS-CAMPANES & BENAHAVIS (Málaga) & $10 / 8 / 68$ & 1.338 & 37.000 \\
\hline HACIENDA DE LA MANGA DE SAN JAVIER & SAN JAVIER (Murcia) & 27/1/69 & 280 & 36.400 \\
\hline EL CUARTÓN & TARIFA (Cádiz) & $17 / 8 / 71$ & 540 & 33.000 \\
\hline HACIENDA DE LA MANGA DE CARTAGENA & CARTAGENA (Murcia) & $12 / 9 / 66$ & 185 & 21.000 \\
\hline RIOMAR & TORTOSA (Tarragona) & $17 / 1 / 70$ & 375 & 20.000 \\
\hline ALMERIMAR & EL EJIDO (Almería) & $11 / 12 / 67$ & 232 & 16.190 \\
\hline COMPLEJO RESIDENCIAL CAMPOAMOR & ORIHUELA (Alicante) & $6 / 5 / 69$ & 25 & 13.160 \\
\hline PLAYA DE MATALASCAÑAS & ALMONTE (Huelva) & $16 / 9 / 69$ & 735 & 10.890 \\
\hline LA ZENIA & ORIHUELA (Alicante) & $16 / 7 / 68$ & 112 & 8.000 \\
\hline AGUADULCE & ROQUETAS DE MAR (Almería) & $10 / 10 / 64$ & 68 & 7.000 \\
\hline MAZAGÓN & PALOS DE LA FRONTERA (Huelva) & $16 / 7 / 68$ & 131 & 6.932 \\
\hline SOTOGRANDE & SAN ROQUE (Cádiz) & $20 / 9 / 65$ & 1.212 & 6.400 \\
\hline LAS MARINILLAS & ALMERÍA (Almería) & $1 / 7 / 71$ & 55 & 6.300 \\
\hline SANTA POLA DEL ESTE & SANTA POLA (Alicante) & $20 / 9 / 65$ & 72 & 6.000 \\
\hline ROQUETAS DE MAR & ROQUETAS DE MAR (Almería) & $6 / 3 / 67$ & 100 & 6.000 \\
\hline BAHÍA DE MAZARRÓN-SAN GINÉS & CARTAGENA (Murcia) & $22 / 2 / 68$ & 91 & 5.100 \\
\hline LOS ÁNGELES DE LA BARROSA & CHICLANA (Cádiz) & $7 / 11 / 66$ & 158 & 5.000 \\
\hline LAS FUENTES & ALCALÁ DE CHIVERT (Castellón) & $1 / 2 / 66$ & 61 & 4.675 \\
\hline PLAYA HONDA & CARTAGENA (Murcia) & $11 / 2 / 67$ & 54 & 4.500 \\
\hline PLAYA DE GRANADA & MOTRIL (Granada) & $22 / 1 / 68$ & 57 & 4.440 \\
\hline EL ALAMILLO & MAZARRÓN (Murcia) & $18 / 3 / 68$ & 53 & 3.754 \\
\hline PLAYA DE LOS PORTICHUELOS & SAN ROQUE Y LA LÍNEA (Cádiz) & $6 / 5 / 69$ & 50 & 3.740 \\
\hline BAHÍA DE MAZARRÓN-EL MOJÓN & CARTAGENA (Murcia) & $22 / 1 / 68$ & 51 & 3.100 \\
\hline HACIENDA DOS MARES & CARTAGENA (Murcia) & $25 / 2 / 69$ & 61 & 1.900 \\
\hline HORIZONTES DE QUINTANA & ALGECIRAS (Cádiz) & $26 / 11 / 68$ & 348 & 1.294 \\
\hline \multirow[t]{2}{*}{ ISLA DE LA TOJA } & EL GROVE (Pontevedra) & $12 / 9 / 66$ & 922 & 841 \\
\hline & & & 11.390 & 463.796 \\
\hline
\end{tabular}




\begin{tabular}{|c|c|c|c|c|}
\hline \multicolumn{5}{|l|}{ Zonas turísticas litorales consolidadas } \\
\hline NUEVA ANDALUCÍA & MARBELLA (Málaga) & $11 / 11 / 64$ & 1.005 & 75.000 \\
\hline BAHÍA NOVA & ARTÁ (Baleares) & $27 / 9 / 74$ & 350 & 20.000 \\
\hline SON PARC & MERCADAL (Baleares) & $29 / 3 / 72$ & 258 & 19.000 \\
\hline PLAYA DE LAS TERESITAS & SANTA CRUZ (Tenerife) & $22 / 1 / 68$ & 90 & 14.020 \\
\hline CALA TIRANT & MERCADAL (Baleares) & $2 / 3 / 71$ & 106 & 12.780 \\
\hline EL GUINCHO & SAN MIGUEL (Tenerife) & 20/4/67 & 166 & 12.515 \\
\hline CALA SALIONS & TOSSA DE MAR (Gerona) & $31 / 5 / 66$ & 138 & 12.420 \\
\hline TORREMUELLE & BENALMÁDENA (Málaga) & $11 / 12 / 67$ & 45 & 10.970 \\
\hline CALA TURQUESA & CIUDADELA (Baleares) & $4 / 10 / 75$ & 110 & 9.798 \\
\hline COSTA TAURITOS & MOGAN (Las Palmas) & $16 / 8 / 71$ & 169 & 9.217 \\
\hline CALAS DE MALLORCA & MANACOR (Baleares) & $4 / 4 / 66$ & 350 & 8.700 \\
\hline PLAYA DE FORNELLS & MERCADAL (Baleares) & 2/5/73 & 62 & 7.280 \\
\hline PLAYA DE LAS GAVIOTAS & SANTA CRUZ (Tenerife) & $12 / 6 / 69$ & 86 & 5.078 \\
\hline LAS GAVIOTAS & MURO (Baleares) & $26 / 2 / 68$ & 46 & 5.068 \\
\hline CALLAO SALVAJE & ADEJE (Tenerife) & $16 / 9 / 69$ & 70 & 4.981 \\
\hline ACANTILADO DE LOS GIGANTES & SANTIAGO DEL TEIDE (Tenerife) & $10 / 10 / 64$ & 28 & 4.245 \\
\hline DOMINIO RESIDENCIAL GIVEROLA & TOSSA DE MAR (Gerona) & $10 / 10 / 64$ & 90 & 2.150 \\
\hline \multirow[t]{2}{*}{ PINOMAR } & MARBELLA (Málaga) & $22 / 7 / 65$ & 10 & 936 \\
\hline & & & 3.179 & 234.158 \\
\hline \multicolumn{5}{|l|}{ Estaciones de esquí } \\
\hline LA PINILLA & CEREZO DE ARRIBA (Segovia) & $25 / 11 / 71$ & 750 & 30.000 \\
\hline SUPER ESPOT & ESPOT (Lérida) & $14 / 3 / 74$ & 471 & 10.000 \\
\hline ESTACIÓN DE ESQUÍ DE CERLER & BENASQUE (Huesca) & $7 / 11 / 66$ & 2.387 & 8.000 \\
\hline MONTAÑA DE LLESUY & SORT (Lérida) & $20 / 3 / 67$ & 100 & 6.090 \\
\hline VALLE DE LA BARRANCA & NAVACERRADA (Madrid) & $30 / 7 / 69$ & 113 & 4.000 \\
\hline VALCOTOS & RASCAFRÍA (Madrid) & $30 / 8 / 75$ & 268 & 3.885 \\
\hline SOLYNIEVE & GRANADA (Granada) & $19 / 10 / 65$ & 40 & 3.800 \\
\hline ASTÚN & JACA (Huesca) & $27 / 9 / 75$ & 920 & 3.670 \\
\hline EL FORMIGAL & SALLENT DE GÁLLEGO (Huesca) & $20 / 5 / 67$ & 41 & 1.800 \\
\hline EL SERRALLO & GRANADA (Granada) & $20 / 1 / 70$ & 30 & 1.800 \\
\hline VALLE DE ARÁN-NÚCLEO I & NAUT ARAN (Lérida) & $27 / 1 / 70$ & 48 & 1.600 \\
\hline \multirow[t]{2}{*}{ BALNEARIO DE PANTICOSA } & PANTICOSA (Huesca) & $22 / 3 / 66$ & 37 & 830 \\
\hline & & & $5.205,3$ & 75.475 \\
\hline
\end{tabular}




\begin{tabular}{|c|c|c|c|c|}
\hline \multicolumn{5}{|l|}{ Urbanizaciones de segunda residencia } \\
\hline COSTA DE MADRID-VIRGEN LA NUEVA & SAN MARTÍN DE VALDEIGLESIAS (Madrid) & $10 / 4 / 67$ & 475 & 33.000 \\
\hline CESALPINA & SANTA COLOMA DE CERBELLÓ (Barcelona) & $30 / 7 / 69$ & 85 & 7.650 \\
\hline MONTE MONCAYO & TARAZONA (Zaragoza) & $16 / 1 / 67$ & 105 & 3.220 \\
\hline LOS ROBLES & TORRELODONES (Madrid) & $27 / 7 / 68$ & 52 & 3.110 \\
\hline CIUDAD RESIDENCIAL EL BOSQUE & CHIVA, GODELLETA Y TORRENTE (Valencia) & $15 / 9 / 69$ & 75 & 3.027 \\
\hline SANTA MARÍA DE CANIDE & OLEIROS (La Coruña) & $31 / 5 / 66$ & 35 & 2.642 \\
\hline URBANIZACIÓN MONTE PICAYO & SAGUNTO (Valencia) & $14 / 8 / 65$ & 30 & 2.100 \\
\hline LAS BRISAS & SACEDÓN (Guadalajara) & $22 / 1 / 68$ & 35 & 1.812 \\
\hline LAS PAJANOSAS & GUILLENA (Sevilla) & $26 / 11 / 68$ & 207 & 1.000 \\
\hline AREA DE REFUGIO DEL MONTSENY & SAN PEDRO DE VILAMAJOR (Barcelona) & $25 / 11 / 71$ & 173 & 800 \\
\hline LAS ANCLAS & PAREJA (Guadalajara) & $27 / 7 / 68$ & 65 & 685 \\
\hline \multirow[t]{2}{*}{ LA JUNQUERA DEL BAO } & VIGO (Pontevedra) & $20 / 3 / 67$ & 7 & - \\
\hline & & & 1.344 & 59.046 \\
\hline \multicolumn{5}{|l|}{ Promociones turísticas de interior } \\
\hline LA NAVA DE SAN LUIS & PARAUTA (Málaga) & $16 / 1 / 67$ & 856 & 33.000 \\
\hline EL SANTISCAL & ARCOS DE LA FRONTERA (Cádiz) & $25 / 2 / 69$ & 154 & 11.500 \\
\hline CLAROS DE LA RIOJA & (Logroño) & $14 / 10 / 70$ & 78 & 9.370 \\
\hline VALLE VERDE DE ULZAMA & VALLE DE ULZAMA (Navarra) & $7 / 4 / 70$ & 29 & 2.163 \\
\hline PARQUE DE CUBILLAS & ALBOLOTE (Granada) & $30 / 6 / 71$ & 40 & 1.020 \\
\hline \multirow[t]{2}{*}{ ALTO HERRERA } & SAMANIEGO (Álava) & $7 / 5 / 69$ & 39 & 112 \\
\hline & & & 1.196 & 57.165 \\
\hline
\end{tabular}

FUENTE: Centro de Documentación Turística de España (Secretaría General de Turismo)

La importancia cuantitativa de los centros aprobados fue decreciendo a lo largo de los años, debido a la progresiva disminución de su tamaño, tanto en hectáreas ocupadas (que pasa de las 400-500 ha de los primeros años, a menos de 300 en los últimos), como en plazas previstas (de 15.000 plazas de media a unas 11.000). Ello está en relación con el tipo de iniciativas que se fueron acogiendo a los beneficios de la ley: del protagonismo de los grandes centros turísticos litorales de los primeros años a las urbanizaciones de segunda residencia del último periodo.

La mayor parte de los grandes centros son importantes promociones localizadas en tramos del litoral mediterráneo peninsular y del atlántico meridional con un escaso desarrollo turístico hasta ese momento: Isla Canela y Playa de Matalascañas, en Huelva; Sotogrande, Guadacorte y La Alcaidesa, en Cádiz; varias promociones en La Manga del Mar Menor, Murcia. Incluso las promociones del litoral malagueño se ubican en su sector más occidental, menos consolidado hasta ese momento, y que a partir de esta fecha se convertirá en el enclave emblemático de la Costa del Sol: Nueva Andalucía (con el Puerto de Banús) en Marbella, y Benahavís-Campanes. 


\section{NÚMERO DE CENTROS POR ZONAS}

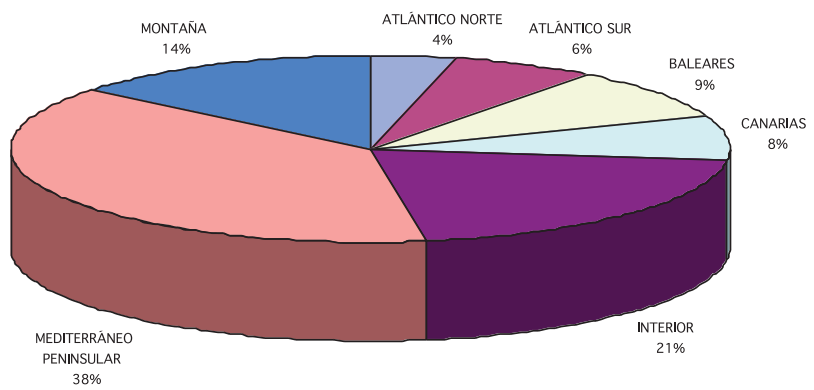

\section{PLAZAS PROGRAMADAS}

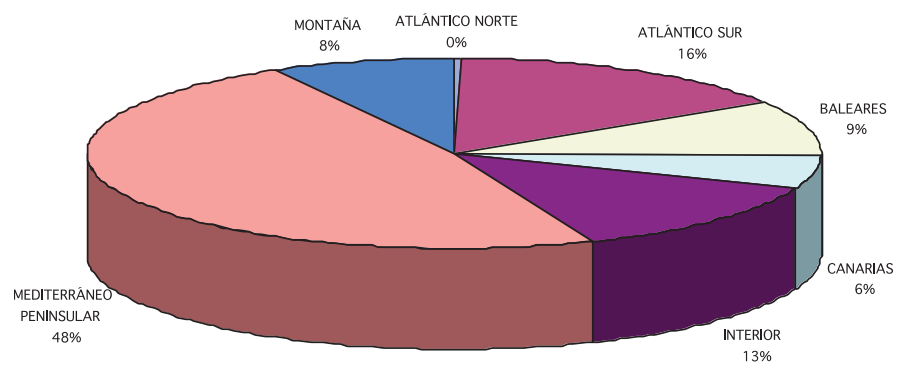

Centros de Interés Turístico Nacional Aprobados (1966-1975). Números de Plazas Previstas.

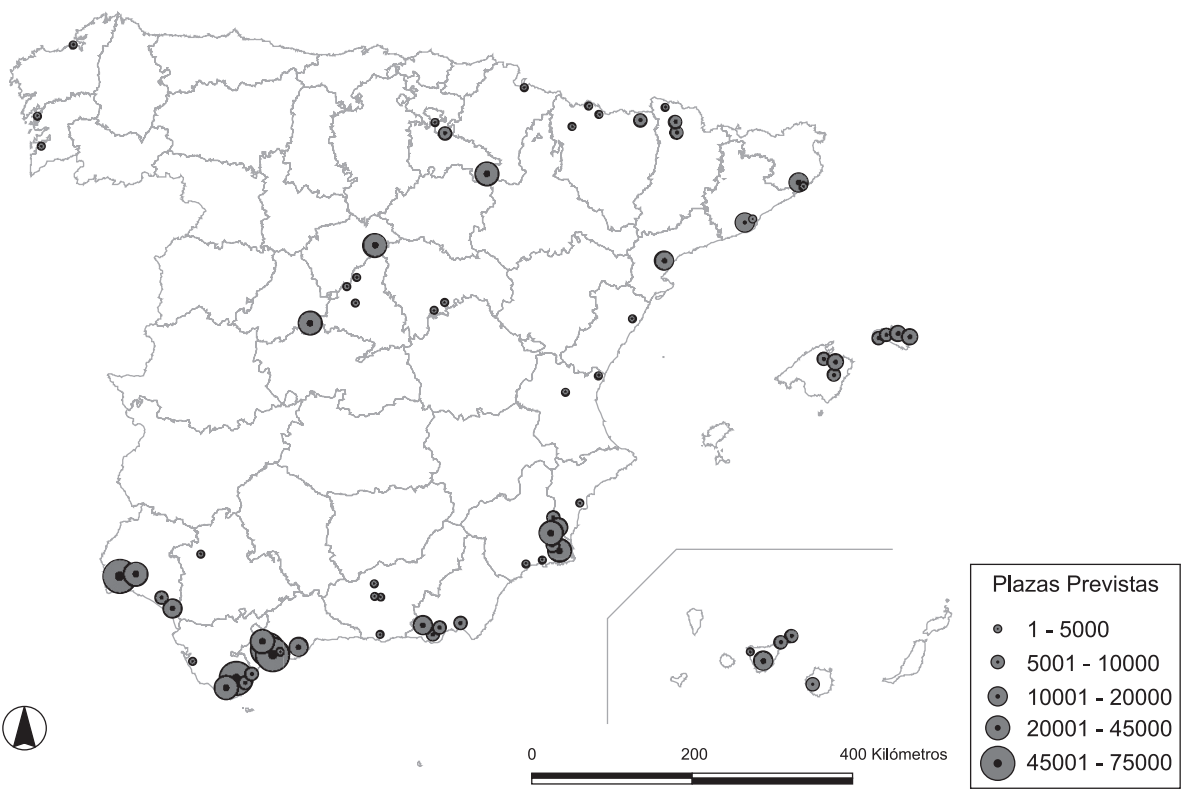


El otro grupo de grandes centros queda integrado por las estaciones invernales: en la provincia de Huesca, Cerler (Benasque) y Astún (Jaca); en Segovia, La Pinilla (Cerezo de Arriba). En estos casos, la inclusión de parte de los dominios esquiables en la declaración del centro explica su importancia superficial, no siempre traducida en un elevado número de plazas de alojamiento previstas.

El resto de grandes centros muestra la variedad de orientaciones, territoriales y de tipo de producto turístico-inmobiliario, que finalmente caracterizó la aplicación de esta figura jurídica: una estación balnearia litoral en el litoral atlántico norte, la de la Isla de la Toja (O Grove, Pontevedra); un gran centro de turismo de interior (el de Parauta, Málaga, en la Sierra de las Nieves); grandes promociones de segunda residencia junto a las grandes ciudades (Costa de Madrid, en San Martín de Valdeiglesias); operaciones en destinos ya consolidados como Baleares (Bahía Nova, en Artá).

\subsection{El desarrollo de las zonas litorales con débil ocupación turística. La Costa de Huelva: el Languedoc-Roussillon español}

La puesta en el mercado de nuevas zonas turísticas era, sin duda, el objetivo central de la política de fomento y ordenación territorial del turismo abordada en aquellos años. Con el objetivo de introducir principios de ordenación racionales, tanto desde la perspectiva de los territorios aún sin explotar como de la calidad de la oferta de alojamientos finalmente obtenida, el Ministerio de Información y Turismo planteó un esquema ideal de actuación que se iniciaba con la elaboración de documentos de planificación territorial sobre las ZITN que posteriormente se desarrollarían con la promoción de CITN. Este esquema se siguió de una manera bastante cercana a los postulados del Ministerio en la costa de Huelva, y en parte en ciertos tramos de la Costa del Sol. Sin embargo, en la mayor parte de los casos el fomento de ciertas zonas turísticas (Costa de Almería, Costa de Cádiz, litoral sur de Alicante y Murcia) se limitó a la aprobación de un determinado número de centros, sin establecerse un mínimo esquema territorial en el que enmarcar dichas actuaciones.

El conjunto de actuaciones de promoción turística desarrolladas en el litoral onubense constituye, sin duda, el mejor ejemplo de la política de promoción de zonas turísticas propugnada desde el MIT. Para ello, el Ministerio ordenó la redacción de un plan director territorial que posteriormente fue parcialmente desarrollado a través de la creación de hasta cuatro CITN (Isla Canela, El Portil, Mazagón y Matalascañas). Estas iniciativas, además de punto de arranque de la puesta en el mercado de la costa de Huelva, formalizaron un modelo turístico basado en la creación de grandes polos junto a la costa (ciudades vacacionales) desconectados de la trama urbana preexistente, que se continuará y consolidará en años posteriores (Santos, 1999).

En 1963 queda definitivamente redactado el denominado Proyecto de Ordenación, Promoción y Desarrollo Turístico de la Costa de Huelva, realizado desde la CIT con la finalidad de producir un instrumento que debía ser observado «en las actuaciones turísticas que pondrán en mercado el magnífico litoral onubense». En este sentido, constituye sin duda un documento pionero al tratarse de la «primera experiencia española en cuanto a aplicación de un desarrollo turístico regional planificado armónicamente en sus directrices básicas» (Memoria MIT, 1964-65, pág. 374).

En el seno de la CIT se tuvo la conciencia de disponer de una ocasión óptima para la puesta en práctica de los presupuestos teóricos defendidos desde la administración turística desde los años 50. No en balde se enfrentaban al «último tramo de la costa española de cualidades turísticas óptimas», y sobre el que podía actuarse unitariamente dando lugar a unos productos turísticos con una alta calidad de servicios desde una gestión única y racio- 
nalizada. Además, esta actuación encajaba plenamente en los presupuestos de la planificación económica que presidía en aquellos momentos el desarrollo nacional, contribuyendo al despegue de un ámbito regional deprimido.

El territorio de acción elegido, así como la propia naturaleza de la actuación administrativa de fomento turístico y su vinculación con la planificación económica, muestran un evidente paralelismo entre esta iniciativa y la puesta en valor del litoral del LanguedocRoussillon, que en aquellos mismos años se estaba desarrollando en Francia. En ambos casos, sobre un ámbito regional deprimido socio-económicamente pero dotado de una costa con grandes posibilidades de desarrollo turístico, se plantea una fuerte actuación pública de puesta en valor para vencer los grandes escollos que habían imposibilitado el desarrollo turístico espontáneo (carácter insalubre de las zonas húmedas litorales características de estos litorales y, en consecuencia, ausencia de un sistema urbano e infraestructural bien desarrollado con posibilidades de acogida turística). En uno y otro caso se optó por la creación de grandes centros balnearios de nueva planta polarizando en ellos el crecimiento de la actividad.

En el caso de Huelva se actúa sobre una franja litoral de aproximadamente $120 \mathrm{~km}$, entre el Guadiana y el Guadalquivir, dotada de magníficas playas de arena enmarcadas por abundantes zonas boscosas, con buen clima y una disposición de la costa (elevada sobre la playa en muchos lugares) particularmente interesante, pues permite construir casi en toda su extensión con visión directa del Océano. La abundancia de zonas húmedas litorales, y su carácter insalubre, explican otra de sus principales características territoriales: la debilidad de su poblamiento. Los principales centros urbanos litorales se ubican en las rías que jalonan la costa, lejos de las playas (es el caso de Huelva, de Isla Cristina o de Ayamonte), mientras que el resto de cabeceras municipales (Cartaya, Lepe, Almonte) se localizan en el interior. Los asentamientos costeros existentes en aquellos momentos no eran más que poblados de pescadores (La Antilla, El Rompido), con algunos chalets de temporada, que comenzaban a formar pequeñas agrupaciones en Punta Umbría o Mazagón. Con la excepción de Punta Umbría, esta ausencia de ayuntamientos verdaderamente arraigados a la costa es otro de los argumentos manejados por la Ponencia para justificar la necesidad de una acción pública estatal de promoción del turismo.

La debilidad del poblamiento explicaba igualmente la carencia de comunicaciones de este sector litoral, favoreciendo «su carácter tranquilo y solitario, su matiz exótico en muchos lugares, el estado casi salvaje en que se hallan muchas extensiones» (Proyecto de Ordenación, pág. 20). Evidentemente, la falta de infraestructura territorial de acogida para un desarrollo espontáneo justificó la necesidad de una intervención pública fuerte que, además de acometer un considerable esfuerzo inversor en materia de infraestructuras, debía dar solución a otros inconvenientes no menores: la situación jurídica de los terrenos y el carácter insalubre de la zona.

La Ponencia estimaba que, a pesar de que el litoral era turísticamente aprovechable en su práctica totalidad (una franja de 1.000 metros a lo largo de $120 \mathrm{~km}=12.000 \mathrm{ha}$ ), la ordenación debía restringirse a un total de 5.000 ha, escalonadas a lo largo de 20 años, y concentradas en 13 zonas, con una capacidad de 341.200 plazas de alojamiento ${ }^{4}$. El Pro-

4 Zona 1. Isla Canela (1.050 ha y 73.500 plazas). Zona 2. Playa del Perdigón (150 ha y 12.000 plazas). Zona 3. Playa de la Antilla (250 ha y 20.000 plazas). Zona 4. Nueva Umbría (450 ha y 27.000 plazas). Zona 5. Faro. El Rompido (250 ha y 20.000 plazas). Zona 6. La Bota. El Portil (500 ha y 35.000 plazas). Zona 7. Punta Umbría (250 ha y 15.000 plazas). Zona 8. El Picacho (240 ha y 21.600 plazas). Zona 9. Mazagón (350 ha y 28.000 plazas). Zona 10. Torre del Loro (200 ha y 16.000 plazas). Zona 11. Torre La Higuera. Asperillo (900 ha y 54.000 plazas). Zona 12. Matalascañas (250 ha y 17.500 plazas). Zona 13. Coto Doña Ana (160 ha y 1.600 plazas). 
yecto, desde su carácter indicativo, además de localizar los núcleos de preferente desarrollo plantea un esquema general pero bastante detallado de las obras e instalaciones precisas para el acondicionamiento turístico de los mismos, que debía ser observado por la acción inversora estatal (carreteras, aeropuerto, abastecimiento de aguas).

El plan adquiere una mayor concreción y nivel de detalle cuando aborda dos cuestiones de especial significación para el desarrollo inmediato del uso turístico: el carácter insalubre de la zona y la situación jurídica de los terrenos. La acción de saneamiento biológico es abordada con carácter preferente e ineludible, previamente a todo intento de ordenación turística. La importancia de los focos de mosquitos, su diseminación a lo largo de todo el litoral, a veces contiguos a los principales núcleos habitados (Ayamonte, Isla Cristina, incluso Huelva), y la presencia de especies de los géneros anopheles y myzonnia (con el consiguiente riesgo de paludismo) hacían necesaria una intervención profunda. Con este motivo, se incorpora al proyecto el Plan de saneamiento biológico formulado desde la Dirección General de Sanidad, y que preveía la intervención sobre un total de 20.000 ha (1.500 de ellas de gran peligrosidad, junto a las poblaciones antes mencionadas). En ellas se desarrollarían tratamientos con insecticidas (tres veces por año durante cinco años consecutivos) en los cursos de agua peligrosos, así como en las viviendas. Mediante esta intervención se pensaba lograr una situación aceptable que permitiese el inicio de los trabajos de urbanización, estimando que el avance de los mismos ayudaría a que el problema fuera progresivamente controlado.

En relación con la situación jurídica de los terrenos, el problema era así percibido:

«La casi totalidad del litoral se encuentra en manos de organismos públicos, lo que imposibilita que la propiedad del suelo haya entrado en órbita de mercado competitivo. El sistema de concesiones administrativas, si bien ha promovido un cierto pero anárquico y poco pujante desarrollo turístico de algún punto muy concreto y específico del litoral, no es el más apto para atraer sobre la zona las inversiones ...» (Proyecto de Ordenación, pág. 25).

En efecto, buena parte de los terrenos potencialmente desarrollables poseían carácter público, y sobre ellos se habían desarrollado pequeñas agrupaciones turísticas carentes de toda ordenación de conjunto mediante el recurso a concesiones administrativas. En resumen, se planteaban las siguientes situaciones:

a. Montes públicos catalogados de los Ayuntamientos (Ayamonte, Punta Umbría, Cartaya, Isla Cristina, Moguer) o del Patrimonio Forestal del Estado (desde el Odiel al Coto de Doñana).

b. Terrenos abandonados por el mar (y por tanto que pasan a integrar el Patrimonio del Estado), pero sobre los que existían varios miles de chalés ilegales (La Antilla, por ejemplo).

c. Abundantes terrenos marismeños, «fáciles de desecar y sanear, proporcionando solares magníficamente situados para la explotación turística».

A ello había que unir situaciones jurídicas poco claras sobre determinados terrenos de titularidad privada. Es el caso de notables extensiones del litoral dadas a censo dentro del ámbito de lo que fue el Marquesado de Astorga, cuyo régimen no había sido respetado inscribiéndose las fincas a nombre de los censatarios.

Sobre los terrenos públicos se propugnaba la siguiente solución:

«Se trata de conseguir que los Organismos públicos desafecten de su dominio una faja costera, de un kilómetro de profundidad media, paralela al mar, a fin 


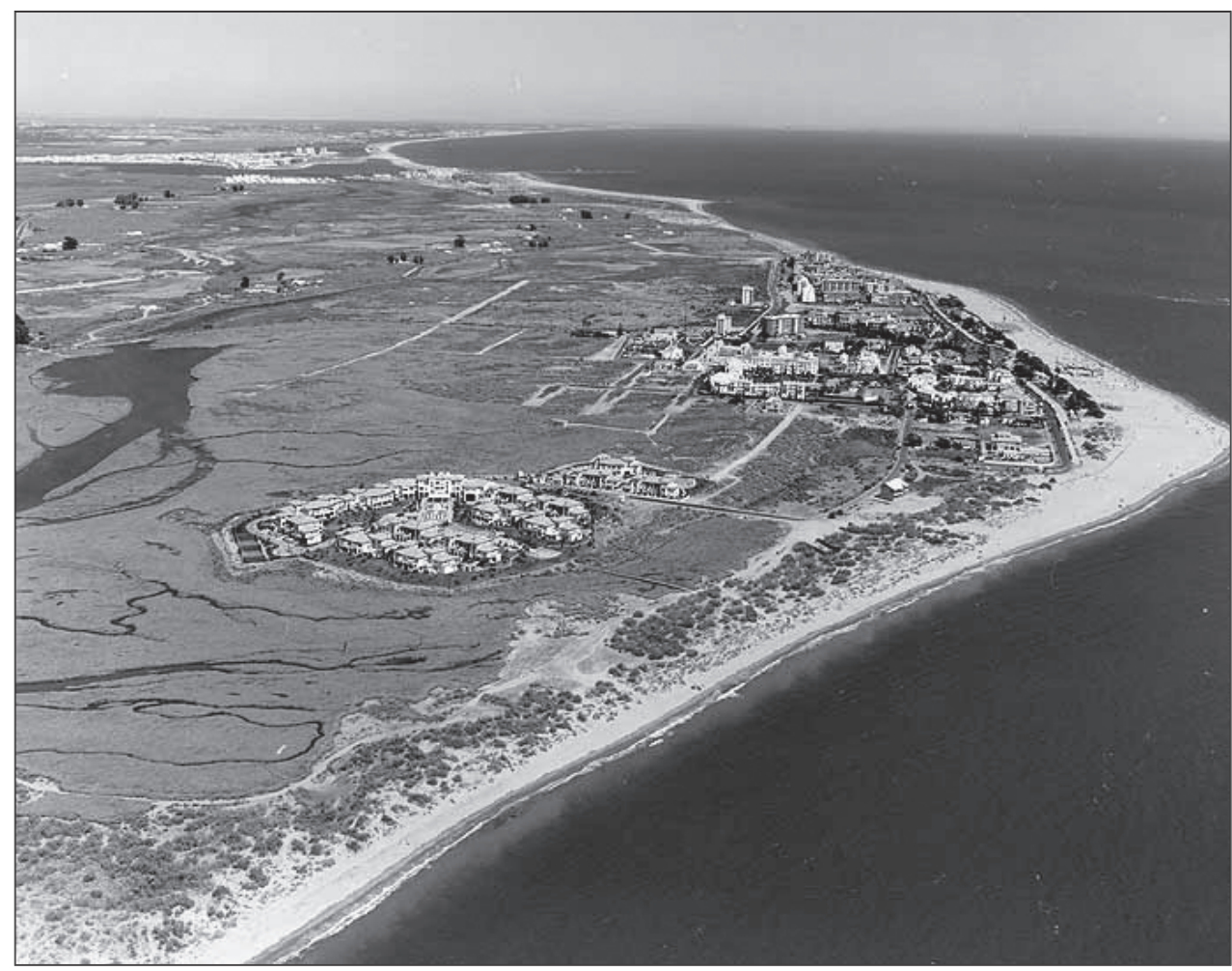

Isla Canela (Ministerio de Medio Ambiente. Guía de playas españolas. http://www.mma.es/costas/ guia_playas/)

de que, una vez dotadas de comunicaciones y suministros básicos, entre en la órbita privada» (Proyecto de Ordenación, pág. 25).

En general se consideraba que una de las primeras líneas de intervención necesarias y previas a la ordenación era una vasta labor de deslinde y saneamiento jurídico de la propiedad que permitiese la posterior venta de solares. Para ello se hace referencia a las necesarias disposiciones legislativas de desafectación, pero, sobre todo, a una utilización de la Ley de Centros y Zonas en toda su amplitud interpretativa.

En fin, un plan director completo, desde sus objetivos, análisis y diagnóstico de recursos territoriales y demandas potenciales, criterios de ordenación y líneas de intervención, junto con su correspondiente estudio económico-financiero, que realmente poseía una gran modernidad para su momento. Evidentemente, aunque en los años posteriores no se establecería una gestión territorial directamente amparada en dicha programación, el Proyecto ha sido una referencia válida para la acción de desarrollo turístico posterior, y muy especialmente en lo que se refiere a la aprobación de los CITN de esta provincia.

Desde el mismo momento en que se está redactando el plan director de la Costa de Huelva comienzan a aprobarse los CITN que abrirán el camino del desarrollo turístico de la zona, empezando por el mayor de todos ellos (Isla Canela), a los que seguirán los de El Portil, Mazagón y Matalascañas. 
Se localizan de una manera aproximadamente simétrica al este y oeste de las rías del Tinto y el Odiel: Isla Canela y El Portil en el sector occidental, y Mazagón y Matalascañas en el oriental. De esta manera se generaban cuatro polos de crecimiento distribuidos de una manera regular por el litoral, si bien con una importancia cuantitativa netamente diferenciada. Mientras que en la zona occidental se plantean dos centros con más de 40.000 plazas cada uno, los de la costa oriental tienen un tamaño mucho menor. Por otro lado, en la zona occidental ya se situaban dos implantaciones espontáneas importantes: Punta Umbría, a la que se adosaba el Portil, y La Antilla (Lepe), por lo que se opta claramente por una concentración del crecimiento en este sector.

La gestión del suelo fue uno de los asuntos de mayor trascendencia en el desarrollo de estos centros, pues sólo Matalascañas era de propiedad privada. En Isla Canela y El Portil se trataba de montes públicos municipales; en Mazagón, del Patrimonio Forestal del Estado. En los tres casos, la movilización del suelo exigió de una previa desclasificación para poder disponer de tales terrenos. Mientras que en el primer caso (Matalascañas) los propietarios de suelo fueron los promotores del CITN, en el caso de Isla Canela se creó una sociedad mixta de urbanización (suelo público y capital privado), en tanto que en El Portil y Mazagón se procedió pura y simplemente a vender los terrenos a los promotores, donde aparecen capitales financieros extranjeros junto a la presencia de grandes empresas de obra pública nacionales (Valenzuela, 1985, pp. 298-300).

La definitiva consolidación de la costa de Huelva como destino turístico aún no puede darse por culminada, si bien en los decenios de los 80 y 90 se ha producido un considerable aumento de la oferta de alojamiento cuya implantación territorial ha seguido, en líneas generales, las directrices marcadas por el primer Proyecto de Ordenación, Promoción y Desarrollo Turístico de la Costa de Huelva. En todo caso, la ausencia de una política territorial coordinada ha impedido que los escollos a la promoción turística provocados por la ausencia de un sistema de asentamientos tradicionales, y la consiguiente falta de vertebración viaria, no hayan sido todavía superados, presentándose una grave ineficiencia del actual modelo territorial. Sólo desde la planificación ambiental y mediante la protección de espacios naturales se ha conseguido una parcial preservación de los elevados valores ambientales de la zona, que en todo caso se hallan en una situación de elevada fragilidad, pues los proyectos de desarrollo todavía pendientes pueden duplicar la capacidad de algunos sectores en los próximos años.

\subsection{El papel de los CITN en los sectores litorales de desarrollo turístico bien implantado. Las Canarias}

Tras los centros implantados en zonas «vírgenes», el siguiente gran grupo de CITN se sitúa en litorales que ya se habían definido claramente como destinos turísticos bien establecidos: Costa Brava, Costa del Sol, Baleares y Canarias. La legislación de Zonas y Centros establecía entre sus objetivos no sólo la puesta en el mercado de nuevos territorios sino también la ordenación racional de ciertos sectores más consolidados. Dicho proceso de declaración fue iniciado tanto en la Costa Brava como en la Costa del Sol, sin que en ninguno de los dos casos se llegara a la efectiva declaración ${ }^{5}$.

5 En el caso de la Costa del Sol se avanzó en la elaboración de diferentes documentos de planificación: Estudio para la ordenación turística de la Costa del Sol (1955), Proyecto de ordenación de la Costa del Sol (1959), Estudio para el desarrollo turístico de la Costa de Málaga al Cabo de Gata (1963), Plan de promoción turística de la Costa del Sol (1967). 
En todo caso, la ubicación de los centros sirvió en buena medida para ampliar la colonización turística de lugares hasta ese momento apenas desarrollados: es el caso del litoral sur de Tenerife, en Canarias; de Menorca, en Baleares; o incluso de Marbella, donde el gran centro de Nueva Andalucía (el mayor de todos) supuso el detonante del posterior proceso urbanizador del municipio, además de otorgarle una inequívoca imagen de calidad que ha mantenido hasta la actualidad.

Los CITN tuvieron en Canarias una significación reducida tanto en el conjunto de la urbanización turística como en el total de plazas y superficie ocupada. Además, su consolidación final y su ligazón con el resto del espacio urbano-turístico fue irregular, con desarrollos parciales y algunos nunca iniciados. Incluso es exagerado referirse al conjunto del archipiélago, dado que de los seis Centros finalmente aprobados cinco lo fueron en la isla de Tenerife y uno en la de Gran Canaria, quedando por tanto al margen del fenómeno la mayor parte del espacio insular. Por tanto, más que en su significación cuantitativa, su mayor importancia radica en su perfecta inserción en la evolución del turismo canario en el momento de su definitiva consolidación dentro de las corrientes del turismo de masas, y de manera específica en lo que ha sido calificado como «el triunfo del sur» (Santana, 1992): los tres Centros de Interés Turístico del sudoeste de Tenerife y el del sur de Las Palmas, en el municipio de Mogán, actuaron, junto con otras urbanizaciones, a modo de cabeza de puente a partir de los cuales se fueron consolidando grandes conjuntos urbano-turísticos (Cáceres, 2002).

El resultado actual del sudoeste de Tenerife es la suma por agregación de actuaciones urbano-turísticas dispersas de muy diferente magnitud y características, promovidas mediante planes parciales, como desarrollo de plan general y sin plan general, planes especiales turísticos (a partir de 1968), así como tres CITN. El primero en concederse (1964), y que en gran medida es uno de los aldabonazos para el desarrollo en el sudoeste de Tenerife, es Acantilado de los Gigantes. Se trata de un desarrollo turístico situado en el municipio de Santiago del Teide, y que si bien no forma parte del conjunto de Playa de las Américas, ha acabado conformando en torno al núcleo tradicional de Puerto de Santiago un foco de cierta importancia, junto con Playa de la Arena.

El segundo CITN fue concedido en 1967 también en Tenerife, en el municipio de San Miguel, muy cerca de donde después se construiría el aeropuerto Reina Sofía. Este Centro, de urbanización y construcción muy recientes, se encuentra igualmente fuera del continuo de Las Américas, aunque relativamente cerca de la urbanización Costa del Silencio (Arona, 1963), una de las primeras en aprobarse de todo el conjunto aunque en la actualidad se encuentra relativamente aislada de la zona de mayor desarrollo.

A partir de este momento se inicia el desarrollo en lo que actualmente es el núcleo gravitatorio del conjunto turístico del sudeste tinerfeño. En 1968 se aprueba el primer plan parcial de Las Américas, en Adeje, e inmediatamente, en este mismo municipio, el CITN de Callao Salvaje (1969), a los que siguen los planes parciales o especiales de La Caleta (1970 en Adeje), Pal-Mar (1970, en Arona), Los Cristianos (1971, en Arona), Marazul (1971, Adeje), Playa Paraíso (1972, Adeje), y el segundo plan parcial denominado Las Américas (1972, Arona).

En cuanto a Gran Canaria, el único CITN es Costa Tauritos, en el municipio de Mogán y al oeste del conjunto de Maspalomas Costa Canaria, que se desarrollaba en su totalidad en el término municipal de San Bartolomé de Tirajana. Se trata de un Centro tardío (1971), concedido cuando el proceso urbanizador, en un principio centrado en Playa del Inglés y San Agustín, se empieza a desplazar hacia el oeste, desbordando al término municipal de Mogán con unas características muy diferentes a lo que hasta entonces se venía haciendo en Maspalomas: varios promotores y propietarios, mayor dispersión y densidades, ocupación de los barrancos y mayor impacto ambiental, etc. 
Para acabar esta inserción de la concesión de CITN en la evolución del turismo canario, señalar que en Tenerife se concedieron otros dos, pero en este caso totalmente al margen de los procesos generados por el turismo internacional, y dirigidos en gran medida a una clientela regional. Se trata de Playa las Gaviotas (1969), una urbanización de poco más de 50 ha. en San Andrés, al noreste de la capital, y Playa de las Teresitas (Santa Cruz, 1968), que no dio lugar a un desarrollo urbano sino a la construcción de una playa artificial al servicio de la capital provincial.

\subsection{El fomento del turismo de nieve. El ejemplo pirenaico}

El fomento del turismo de nieve fue uno de los objetivos siempre presentes en la administración, ya desde los trabajos derivados del primer Plan Nacional de Turismo en los años cincuenta. El Estudio para la ordenación turística del Pirineo español realizado en 1960 por la Secretaría General para la Ordenación Económico-Social, valoraba las posibilidades de esta zona al mismo nivel que las de la Costa del Sol, planteando iniciativas para su desarrollo que tenían en el Pirineo francés su principal referente. En esta línea, además de formular diferentes propuestas generales de mejora de las comunicaciones internas y con el exterior, señalaba la conveniencia de iniciar la construcción de grandes estaciones invernales. Aunque el trabajo carecía por completo de una evaluación de los recursos existentes para la práctica del esquí, ya indicaba las grandes posibilidades del Pla de Beret, así como de los valles aragoneses de Tena y Benasque; igualmente, siguiendo el ejemplo francés, defendía la conveniencia de desarrollar las posibilidades de alojamiento de los balnearios de altura.

Cuando la CIT comienza, ya en los años sesenta, el desarrollo de las ponencias que debían desembocar en un nuevo y definitivo Plan Nacional, el turismo de nieve aparecía como uno de los elementos clave de la nueva estrategia, pues ponía en valor territorios no explotados hasta ese momento al tiempo que contribuía a equilibrar la fuerte estacionalidad veraniega de la actividad turística en España. En este sentido, un informe sobre estaciones turísticas de invierno elaborado por la CIT establecía la conveniencia de promover con carácter inmediato este tipo de equipamientos en Sierra Nevada, Sierra del Guadarrama y Pirineos, y en esta línea se crearon sendas ponencias que dieron lugar a los proyectos de ordenación, promoción y desarrollo turístico de Sierra Nevada y de Navacerrada-Cotos.

Aunque en el caso de Pirineos no se llegó a crear una ponencia en el mismo sentido, fue, sin embargo, el ámbito donde se aplicó de una manera más consecuente el esquema zona / centros, de manera similar a la ya analizada para el caso de la Costa de Huelva, pero en este caso sin formalizarse en un plan director y con una evidente falta de evaluación global sobre las posibilidades existentes. De nuevo, como en Huelva, la analogía con la actuación francesa de fomento de las estaciones invernales en Alpes y Pirineos que, conforme a la estrategia marcada por la DATAR, se estaba llevando a cabo en esos momentos es inmediata; pero al igual que en el caso de litoral onubense, la formalización de esta voluntad intervencionista de fomento por parte de la administración finalmente se tradujo casi únicamente en la aprobación de 7 centros en las provincias de Lérida y Huesca, además del apoyo a algunas actuaciones infraestructurales imprescindibles para su puesta en marcha.

Los siete Centros aprobados en la montaña pirenaica jugaron un papel clave en el lanzamiento turístico de la zona apoyado en sus posibilidades para la práctica de deportes de invierno, que hasta ese momento se limitaba a unos pocos lugares tradicionales a favor de sus facilidades de acceso por ferrocarril (Candanchú, Nuria y La Molina) (Fernández Gárate y otros, 1989), articulando en sus líneas maestras lo que finalmente ha sido el desarrollo del macizo. Con una década de retraso con respecto al Pirineo francés, el desarrollo 
turístico español, que ya había consolidado la actividad en ciertas zonas del litoral, llega a la montaña, planteándose en concreto la construcción de estaciones de esquí del mismo modo que se estaba realizando al otro lado de la frontera. El recurso a la legislación de Centros y Zonas fue, como en ciertas zonas del litoral, el camino jurídico transitado para la promoción de buena parte de las primeras estaciones. En este sentido, la labor de animación y gestión desarrollada por la Unión Turística del Pirineo fue sobresaliente (Fernández Gárate y otros, 1990, pág. 87).

Las primeras estaciones de esta nueva etapa (Baqueira-Beret y Formigal) iniciaron su andadura en 1964 como estaciones integradas, vinculando las instalaciones dirigidas a la práctica deportiva al desarrollo más o menos importante de una oferta de alojamientos (hoteleros y residenciales), siendo posteriormente declaradas CITN. Poco más tarde se inician las obras de Cerler (1966), Masella y Llesuí (1967), Super-Espot (1968), de tal manera que la mayor parte de esta primera generación de estaciones de esquí pirenaicas se realizaron al amparo de la legislación de Centros y Zonas. La anterior vinculación de las estaciones al acceso ferroviario desaparece gracias al aumento de la motorización, que hace especialmente atractivos los emplazamientos que cuentan ya con acceso viario (como Baqueira, junto al Puerto de la Bonaigua), y cuando no es así, es el propio Ministerio de Información y Turismo quien toma a su cargo el necesario acceso rodado (Formigal o Cerler).

El CITN de Panticosa constituye una singularidad. Se vuelve a la tradición pirenaica de vincular la actividad balnearia con la práctica del esquí, con una pequeña actuación junto al casco del pueblo enlazada mediante telesilla con las pistas de esquí (Fernández Gárate y otros, 1990, págs. 90-91). En otro sentido, Astún constituye también un hecho excepcional, por el carácter municipal de su promoción a cargo del Ayuntamiento de Jaca.

Las arriba descritas, junto a las estaciones de La Tuca-Mall Blanc (1972), Port del Comte (1973) y Valter 2000 (1975), conforman la primera generación de nuevas estaciones de esquí integradas, que sitúan al Pirineo español dentro de los destinos turísticos de nieve, dirigidos (a excepción de Baqueira) a una clientela casi exclusivamente nacional y, especialmente, de proximidad.

\subsection{El desarrollo de la segunda residencia. El entorno de Madrid}

Las peticiones de CITN para operaciones de segunda residencia en los alrededores de las principales ciudades españolas fueron muy numerosas, produciéndose algunas declaraciones. El caso de la provincia de Madrid ejemplifica bien estas cuestiones, donde los desarrollos de este tipo de vivienda se ligaron en su justificación teórica a la promoción del turismo de nieve. Los centros aprobados en el entorno de Madrid, tanto en la propia provincia como en las limítrofes de Guadalajara y Segovia poseen en efecto una clara finalidad de segunda residencia en relación con la demanda de la gran ciudad, asociados a elementos particularmente atractivos para la ubicación de este tipo de promociones: la presencia de láminas de agua (con posibilidades de práctica de deportes náuticos) y la proximidad de la alta montaña y, en concreto, la aptitud para la práctica del esquí. Evidentemente esta finalidad se alejaba de alguno de los principios que defendían la aplicación de un régimen fiscal más favorable a los CITN: su contribución a la entrada de divisas al país, pero ello no fue obstáculo para su desarrollo.

Como ya se ha comentado, la promoción del turismo de nieve fue uno de los objetivos centrales planteados desde la CIT. En esta línea, uno de sus planes de promoción y fomento, junto a los de Pirineos y Sierra Nevada, fue dirigido a la Sierra de Guadarrama (1967), planteando un vasto programa de urbanización y desarrollo de las actividades ligadas al aprovechamiento deportivo de la nieve. A la pequeña estación existente en Navacerrada se 
sumaba todo un conjunto de sistemas de remonte que la completaban (futuras estaciones de Valcotos y Valdesquí), propugnando igualmente un ambicioso programa de urbanización en altura, hasta el punto que los equipamientos deportivos no eran sino la oferta complementaria de las grandes operaciones residenciales. Se establecían hasta 11 nuevas zonas esquiables, con alojamientos, en los puertos de la Fuenfría, Navacerrada, Cotos y La Morcuera, además de varios nuevos núcleos a menor altitud conectados con las zonas esquiables mediante transportes mecánicos (valles del Lozoya, de la Barranca, de la Fuenfría, ...) (Barrado, 1999, pp. 289 y ss. y Valenzuela, 1977, pp. 390 y ss).

Algunas de las propuestas de este Proyecto fueron el origen de iniciativas individuales que desembocaron en la tramitación de varios CITN, con la aprobación final de dos de ellos. Uno de los núcleos intermedios de menor altitud pretendía ser desarrollado en el CITN del Valle de la Barranca (sobre el Monte de Utilidad Pública del Pinar de la Barranca), promovido por el propio Ayuntamiento de Navacerrada y aprobado en 1965, pero que no prosperó; como tampoco lo hizo otro proyecto con 30.000 alojamientos en el valle del Lozoya, junto a Rascafría. Ya en los años setenta, se aprueba la actuación de la estación de esquí de Valcotos y de su conjunto residencial, que finalmente sólo se concretó en su vertiente deportiva tras un largo contencioso (Barrado, 1999, págs. 291-3). Por su parte, la estación de la Pinilla y su conjunto residencial, aunque ya en la vecina Sierra de Ayllón, aparece igualmente ligada a la demanda procedente de Madrid.

Sin embargo, los primeros CITN no se ligaron al aprovechamiento recreativo de la nieve sino a las actividades náuticas que, por la lejanía del litoral, busca su acomodo en las láminas de agua artificiales creadas por los embalses. El primero fue el de Costa Madrid, una de las primeras grandes urbanizaciones de la provincia de Madrid dirigida a la segunda residencia, desarrollado sobre terrenos del Monte de Utilidad Pública Dehesa de las Cabreras, junto al pantano de San Juan y perteneciente al municipio de San Martín de Valdeiglesias (Manuel, 1996, pág. 501). De mucha menor importancia es el proyecto ubicado en Sacedón, Las Brisas, junto a los embalses de Entrepeñas y Buendía.

La actuación de Costa Madrid es un buen ejemplo del habitual recurso a montes públicos para el desarrollo de esta figura de ordenación. El Ayuntamiento de San Martín solicitó la declaración de CITN para la urbanización de 475 ha de uno de sus montes junto al embalse, si bien en la memoria del plan se señalaba que dicha actuación era la primera fase de un proyecto más amplio que afectaría a la totalidad de las riberas bajo control municipal. La concesión de la declaración de CITN permitió la descatalogación de la superficie del monte referido, basándose en superior interés general y social del Plan de Promoción Turística sobre la utilidad pública; dicha segregación constituyó la aportación municipal a la sociedad mixta Costa de Madrid, S.A., promotora de la urbanización (Manuel, 1996, págs. 501-2).

\section{Conclusiones}

La Ley de CyZITN construyó un aparato planificador complejo, situado a medio camino entre la planificación sectorial y la territorial, pero no llegó a configurar un nuevo modelo que hubiese establecido una base sólida de coordinación entre ambas perspectivas. Y aquí está su principal problema y la causa de que haya sido objeto de continuas críticas: en la diferencia entre la capacidad de los técnicos del MIT para detectar y dar respuesta a un problema que entonces no era más que incipiente (la necesidad de coordinar la planificación sectorial y la territorial) pero en la final incapacidad para ofrecer una solución legislativa efectiva. Sin embargo, el resultado, analizado con detenimiento, no ha dado lugar ni desde el punto de vista cuantitativo ni cualitativo a los tan negativos resultados que habitualmente se le atribuyen. 
Efectivamente, los promotores de la Ley de CyZITN supieron ver como el turismo español, que entraba en una fase de explosivo crecimiento cuyo resultado es el modelo que hoy conocemos, presentaba dos requerimientos principales. Por un lado, una labor de promoción y desarrollo que le permitiese seguir creciendo, lo que conllevaba importantes inversiones en infraestructuras y servicios; pero junto con las de promoción e inversión, se percibían ya entonces unas necesidades de ordenación y de planificación en el más estricto sentido territorial, apuntándose problemas como la saturación de algunos ámbitos y la necesidad de desarrollar, ordenadamente, otros nuevos. Además, incluía también lo que, salvadas todas las distancias, podríamos calificar de preocupación ambiental y territorial.

La solución de estos problemas debía situarse necesariamente en la combinación de las políticas sectoriales y las territoriales, terreno hacia el cual la Ley de CyZITN apuntó con el desarrollo de Planes de Promoción Turística y Planes de Ordenación Urbana, supuestamente coordinados. Sin embargo, esa estrategia de coordinación se limitó a ser estrictamente puntual desde el punto de vista territorial, sin ser capaz de progresar hasta donde hubiese sido necesario por falta de una más elaborada construcción teórica.

Por lo que se refiere a los efectos territoriales de la aplicación de esta ley, debe resaltarse el papel pionero que buena parte de los centros aprobados jugaron en el despegue turístico de ciertos tramos litorales (Huelva, Cádiz, Almería, Murcia, sur de Alicante), así como del fomento del turismo de nieve (Pirineos, Sierra Nevada), de acuerdo a unos claros principios territoriales para el desarrollo del sector. Todo ello antes de la desvirtuación de estos mismos principios con la derivación hacia la promoción de residencias secundarias en ámbitos metropolitanos que caracterizó la aplicación de la ley en los últimos años de su vigencia.

Por otro lado, la aprobación de estos centros no propició de manera general un proceso descontrolado de recalificación de suelo rústico en ausencia de planeamiento, como también se ha dicho (buena parte de los mismos ya habían realizado este proceso previamente a la declaración como CITN). Por el contrario, la obligada aplicación de determinados estándares de urbanización y servicios para el acceso a los beneficios fiscales de la ley propició la obtención de niveles de calidad en la urbanización y en el producto inmobiliario final claramente superiores a la media, dando lugar a conjuntos todavía hoy claramente reconocibles en este sentido.

\section{Bibliografía}

BARRADO TIMÓN, D. (1999): Actividades de ocio y recreativas en el medio natural de la Comunidad de Madrid. La ciudad a la búsqueda de la naturaleza, Consejería de Medio Ambiente de la Comunidad de Madrid, 345 p.

CÁCERES, E. (2002). Génesis y desarrollo del espacio turístico en Canarias (una hipótesis de trabajo), Las Palmas de Gran Canaria, Universidad de Las Palmas de Gran Canaria, 177 p.

CUÉTARA MARTÍNEZ, J. M. de la (1985): «Los poderes públicos ante el sector turismo», en IV Jornadas de Estudios Económicos Canarios. El Turismo en Canarias. Gobierno de Canarias. Tenerife, pp. 45-57.

FERNÁNDEZ ÁLVAREZ, J. (1965): «La Ley de Centros y Zonas de Interés Turístico Nacional», en Problemas técnicos, económicos y jurídicos de urbanización de zonas turísticas, Instituto de Estudios Turísticos, Vol II, pp. 211-255.

FERNÁNDEZ GÁRATE, L.A.; FERNÁNDEZ-TRAPA DE ISASI, J.; FERNÁNDEZ TRAPA DE ISASI, T. (1990): «Esquí en los Pirineos. Historia para un futuro sin fronteras (II)», Estudios Turísticos, 105: 79-99.

MANUEL VALDÉS, C. (1996): Tierras y montes públicos en la Sierra de Madrid (sectores central y meridional), Madrid, Ministerio de Agricultura, Pesca y Alimentación, 561 p. 
Memorias del Ministerio de Información y Turismo (1962-1969), Sección de documentación de la Secretaría General Técnica.

MINISTERIO DE INFORMACIÓN Y TURISMO. Subsecretaría de Turismo (1962): Algunas ideas para la elaboración de las Bases de un Plan Nacional de Turismo.

RIPOLL MARTÍNEZ, A. (1990): «Els Centres d'Interés Turístic Nacional, el cas de Balears», Treballs de Geografía, 43: 71-82.

SANTANA SANTANA, M. C. (1992): La producción del espacio turístico en Canarias, Las Palmas de Gran Canaria, Cabildo Insular de Gran Canaria, 266 p.

SANTOS PAVÓN, E. (1999): La actividad turística en la costa occidental de Huelva: estructuración sectorial y sostenibilidad territorial. Huelva, Diputación Provincial de Huelva, 140 p.

SERRANO, E. (1966): «Planificación territorial y planificaciones sectoriales (Consideración especial del sector turístico)», en Desarrollo de zonas turísticas, Madrid, Instituto de Estudios Turísticos, pp. 357-402.

TERÁN, F. (1982): Planeamiento urbano en la España contemporánea (1900/1980), Madrid, Alianza Universidad Textos, 651 págs.

TORRES ALFOSEA, F. J. (1997): Ordenación de litoral en la Costa Blanca, Alicante, Universidad de Alicante, $320 \mathrm{p}$.

VALENZUELA RUBIO, M. (1977): Urbanización y crisis rural en la Sierra de Madrid, Madrid, Instituto de Estudios de Administración Local, 534 p.

VALENZUELA RUBIO, M. (1985): «La consommation d'espace par le tourisme sur le littoral andalou: les centres d'intéret touristique national», Revue Géographique des Pyrénées et du Sud-Ouest, 56 (2): 289-312.

VALENZUELA RUBIO, M. (1988): «Los espacios de ocio asociados al agua —o como Madrid se asoma al mar-», en Los paisajes del agua, Valencia, Universidad, pp. 537-553. 